\title{
Effects of hydrophilic polymer-coated polysulfone membrane dialyzers on intradialytic hypotension in diabetic hemodialysis patients (ATHRITE BP Study): a pilot study
}

Kenji Tsuchida ${ }^{1 *}$, Hirofumi Hashimoto ${ }^{2}$, Kazuhiko Kawahara ${ }^{3}$, Ikuro Hayashi ${ }^{4}$, Yoshio Fukata ${ }^{5}$, Munenori Kashiwagi ${ }^{6}$, Akihiro C. Yamashita ${ }^{7}$, Michio Mineshima ${ }^{8}$, Tadashi Tomo ${ }^{9}$, Ikuto Masakane ${ }^{10}$, Yoshiaki Takemoto ${ }^{11}$,

Hideki Kawanishi ${ }^{12}$, Kojiro Nagai ${ }^{13}$ and Jun Minakuchi ${ }^{13}$

\begin{abstract}
Background: Intradialytic hypotension (IDH) is a common clinical manifestation associated with poor prognosis in hemodialysis (HD) patients. HD patients who suffer from diabetic nephropathy (DN) are increasing and diabetes is a major cause of IDH. Effective interventional treatments for IDH have yet to be fully evaluated. The aim of this multicenter prospective study is to clarify the effect of biocompatible hydrophilic polymer-coated polysulfone (PS) membrane, TORAYLIGHT® NV (NV) dialyzers on IDH.

Methods: This is a prospective stratified-randomized multicenter trial. Forty DN patients undergoing HD and receiving two or more times of treatments for IDH per month were enrolled in this study. They were stratified by the number of treatments for IDH and divided to two groups using NV or conventional PS/polyethersulfone (PES) dialyzers. The number of treatments for IDH and changes in systolic blood pressure (SBP) were monitored for 6 months. Patients' demographic and clinical characteristics were also collected at enrollment and the last month of the observation period. In order to clarify the patient characteristics that induced preferable effects by using NV dialyzers, responders were defined as the patients whose average SBP falls in 1 month improved from over $30 \mathrm{mmHg}$ to no more than $30 \mathrm{mmHg}$.
\end{abstract}

Results: The total number of treatments for IDH decreased significantly in NV group, even though pre-dialysis body weight and ultrafiltration volume were similar. In addition, patients using NV had significantly higher post-dialysis SBP and the lowest SBP during HD at sixth month compared as those in PS/PES group. NV responders had valuables suggesting malnutrition and microinflammation, and better lipid profiles than non-responders. However, the representative markers related to nutritional status, arteriosclerosis, and inflammation were not improved by NV treatment.

Conclusions: NV had preferable effects on IDH in DN HD patients. Our results suggest the usefulness of NV as a possible method to deal with IDH. Further studies are needed to clarify the mechanism of NV effects on hemodynamic status.

Trial registration: This study was registered on September 26, 2013, in the University Hospital Medical Information Network-Clinical Trials Registry in Japan (Study ID: UMIN000011872).

Keywords: Diabetic nephropathy, Hemodialysis, Intradialytic hypotension, Multicenter prospective study

\footnotetext{
*Correspondence: tuchiken52@yahoo.co.jp

${ }^{1}$ Tsuchida Dialysis Access Clinic, 2-10-18, Fujiidera DH building 4F, Oka,

Fujiidera-shi, Osaka 583-0027, Japan

Full list of author information is available at the end of the article
} 


\section{Background}

Intradialytic hypotension (IDH) is a common side effect in hemodialysis (HD) patients and occurs in approximately $30 \%$ of all HD sessions [1]. IDH is caused by failure in the compensation of reduced circulating blood volume, and is associated with increased mortality [2-4]. Several patientrelated characteristics and comorbidities increase the risk of IDH, mainly through impairment of the counter-regulatory cardiovascular hemodynamic and neuro-hormonal mechanisms, such as age and diabetes [5]. HD patients are getting older, and diabetes nephropathy (DN) is the major primary disease of HD in Japan [6]. Therefore, IDH-prone patients are also increasing. Several studies of the interventional effects on IDH include comparison of the dialysate components such as sodium and acetic acid [7, 8], and difference of treatment methods [9]. However, few studies investigated the advantage of new dialyzer over conventional dialyzers to deal with IDH [10].

Recently, the state of water molecules in the vicinity of a membrane was reported to play an important role in the biocompatibility of synthetic polymer membranes [11]. A new polysulfone (PS) membrane dialyzer, TORAYLIGHT $^{\bullet}$ NV (NV) (Toray Industries Inc., Tokyo, Japan), was developed by focusing on the state of water molecules on the membrane surface [12]. Yamaka et al. confirmed that platelet adhesion to the membrane surface of NV after HD was less than that of conventional PS dialyzers [13]. Ronco et al. showed that more patients in NV group reached heparin-free dialysis without clotting events during the heparin reduction test, suggesting anti-thrombogenic effects of the NV dialyzers as compared to conventional dialyzers [14]. Hidaka et al. reported that 3-month use of NV reduced the level of platelet-derived microparticles (PDMPs) in HD patients [15]. PDMPs are significantly increased in many prothrombotic diseases, including diabetes, cardiovascular disease and uremia $[16,17]$, which contribute to the development and progression of atherosclerosis [18]. In summary, improved biocompatibility provides some preferable effects on the maintenance of blood vessels, especially in patients with atherosclerosis.

Therefore, in this study, we investigated whether "biocompatible" hydrophilic polymer-coated PS dialyzers improve IDH in HD patients with DN compared as conventional PS/polyethersulfone (PES) dialyzers. In addition, to analyze the effects of "biocompatible" dialyzers on IDH, we also evaluated clinical and serological parameters of anemia, mineral-bone disorder, nutritional status, lipid profile, arteriosclerosis, and inflammation.

\section{Methods}

\section{Study design and subjects}

This study was designed as a prospective stratifiedrandomized multicenter trial. Six dialysis centers participated in this study. IDH was defined as systolic blood pressure (SBP) fall over $20 \mathrm{mmHg}$ from baseline, or presentation of symptoms such as unconsciousness, nausea, chest discomfort, and muscle cramps associated with hypotension requiring any medical interventions [19]. We performed the following treatments for IDH: (1) saline administration, over $100 \mathrm{~mL}$ at one time; (2) decrease of ultrafiltration rate; (3) interruption of ultrafiltration; (4) extracorporeal ultrafiltration method; (5) dialysis discontinuation; (6) leg elevation; and (7) vasopressor administration [20].

Study flow diagram is shown in Fig. 1. The subjects enrolled in this study were DN patients aged between 20 and 80 years with more than 1-year HD vintage using PS, PES, or polyester-polymer alloy (PEPA) dialyzers, who received two or more times of treatments for IDH in 1 month. Exclusion criteria were as follows: (i) treatment by the other renal insufficiency therapies, such as continuous ambulatory peritoneal dialysis and hemodiafiltration; (ii) enrollment in the other clinical study; (iii) anamnestic cardiovascular diseases (heart attack, stroke) within less than 3 months; and (iv) pregnancy, infectious disease, cancer, or acute inflammation. First, in "patientselection period," the number of IDH treatments for each enrolled patient was counted. Then, they were stratified by the number of IDH treatments and allocated to two groups, called NV and PS/PES group. Second, in "pre-observation period" (zero month), the patients' demographic and clinical characteristics were collected. The values of ejection fraction, comorbidities, and antiplatelet/anticoagulant medications in six cases were unavailable because of lack of recent echocardiography data and uncertainty of patient's statements. The number of IDH treatments was counted continuously. Third, in "comparative period" (first to sixth month), dialyzers in NV group were changed to NV and both groups were observed for 6 months. The dialyzers used are shown in Additional files 1 and 2.

There were no differences in dialysis conditions (blood flow rate, dialysate flow rate, dialysis time) including sodium concentration of dialysis fluid between NV and PS/PES groups during the whole study period (from zero to sixth month) (data not shown).

\section{Primary outcome}

Primary outcome was the average of the total number of IDH treatments performed in 1 month, expressed as "total number (times/month/patient)" in each group. Besides, pre-dialysis SBP, post-dialysis SBP, the lowest SBP during HD, SBP fall, pre-dialysis body weight, and ultrafiltration volume were measured in each dialysis session for 1 month and the average value was analyzed. In addition, in order to analyze the characteristics of responders to the dialyzer treatment, we sought the references to find out the cutoff value of average SBP fall 


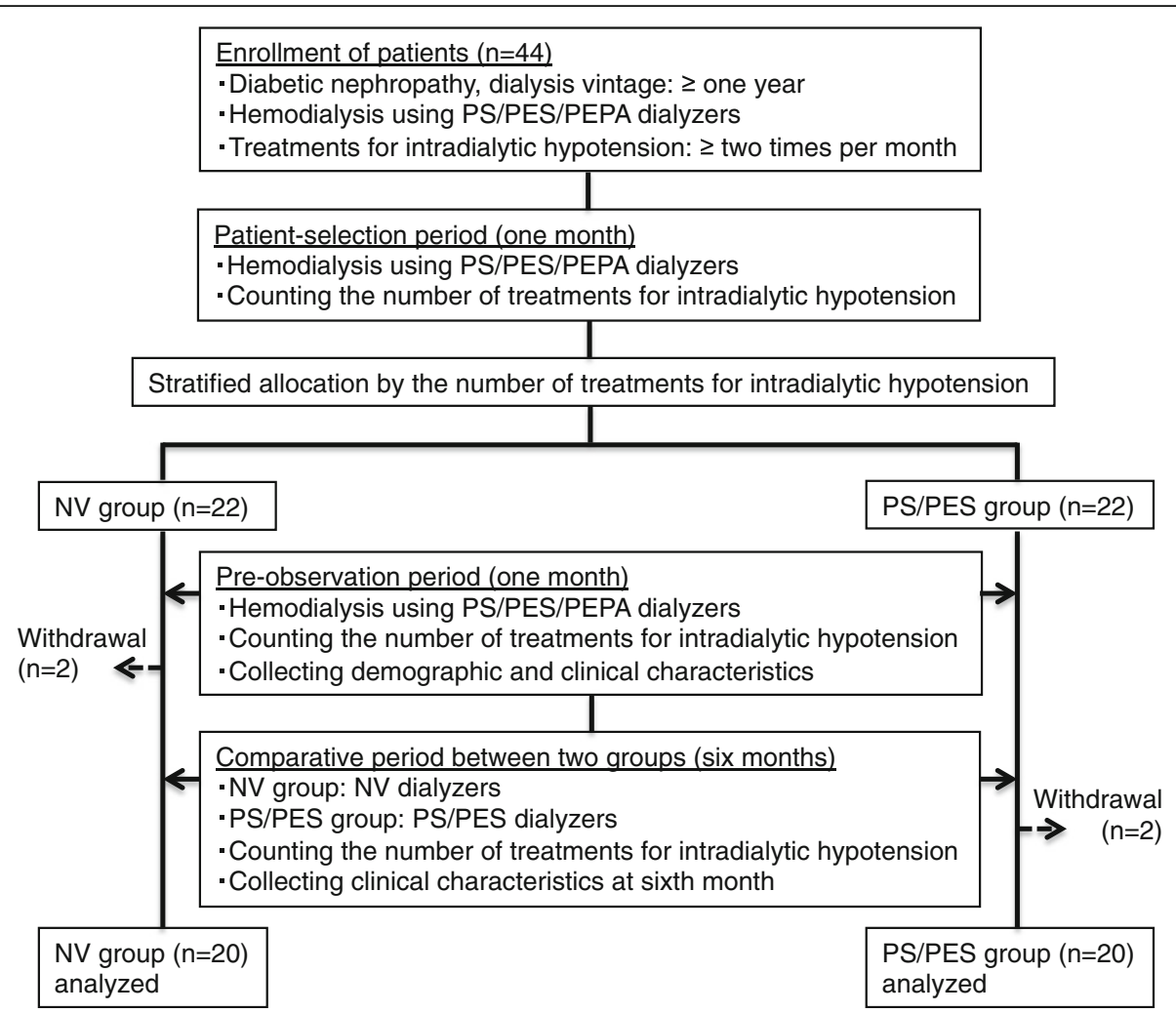

Fig. 1 Study flow diagram. Forty patients completed the entire comparative period. There were two withdrawals from each group (NV group: one moved and the other received a surgical treatment. PS/PES group: one moved and the other changed the modality from HD to hemodiafiltration)

in 1 month that was related to prognosis. However, there is no consensus, evidence-based medical definition for IDH which is related to prognosis [21]. Therefore, we referred to a previous paper investigating the relationship of IDH with mortality in Japanese HD patients reported by Shoji et al. [2]. Shoji et al. described that a greater fall in SBP was associated with increased mortality. This relationship was most clearly demonstrated when the cutoff point for the fall in SBP was set at $40 \mathrm{mmHg}$ (greater fall: $40 \mathrm{mmHg}$ or greater, smaller fall: less than $39 \mathrm{mmHg}$ ). The impact of the intradialytic fall in SBP on mortality was independent of the pre-dialysis SBP. However, Shoji et al. recorded SBP within a single HD session that was the first session of the week, which was different from average SBP fall in 1 month evaluated in our analysis. Shoji et al. also reported that the mean intradialytic falls in SBP in the patients who died and those who survived were about 28 and $32 \mathrm{mmHg}$, respectively. Therefore, the cutoff point for average SBP fall in 1 month at $30 \mathrm{mmHg}$ is reasonable considering the results reported by Shoji et al. Moreover, Chou et al. reported that intradialytic SBP change of less than $15 \mathrm{mmHg}$ and more than $50 \mathrm{mmHg}$ had poor prognosis compared with intradialytic SBP change of 21 to $30 \mathrm{mmHg}$ by analyzing a US-based cohort of 112,013 incident patients over a 5-year period [22]. Consequently, another outcome was defined as the improvement of average SBP fall in 1 month from over $30 \mathrm{mmHg}$ at zero month to no more than $30 \mathrm{mmHg}$ at sixth month. The parameters that strongly associate with IDH such as cardiothoracic ratio (CTR) and the number of antihypertensive drug users were also examined. Blood pressure was measured by oscillometric method.

\section{Secondary outcome}

The following items were evaluated in the beginning of pre-observation period (zero month) and sixth month to clarify the effects of dialyzers: "Nutritional status" (body mass index, albumin); "blood cell count" (white blood cell, platelet); "anemia management" (hemoglobin, the number of erythropoiesis-stimulating agent users, ferritin); "mineralbone disorder control" (phosphate, calcium, intactparathyroid hormone); "lipid" (total cholesterol, triglyceride, high-density lipoprotein cholesterol); "arteriosclerosis and inflammation" (ankle brachial index, homocysteine, pentosidine, high-sensitivity C-reactive protein (hsCRP), pentraxin 3 (PTX3)); and "catecholamine" (adrenaline, noradrenaline, dopamine). Serum homocysteine and pentosidine levels were measured by HPLC assay. hsCRP and PTX3 was measured by latex enhanced immunoturbidimetric assay and ELISA, 
respectively. The analyses of homocysteine, pentosidine, hsCRP, PTX3, and catecholamine were entrusted to LSI Medience Corporation (Tokyo, Japan). Ankle brachial index was measured by oscillometric method.

\section{Statistical analysis}

All values are expressed as mean \pm SD. Statistical analysis was performed using SPSS for Windows version 13.0 (SPSS, Inc., Chicago, IL, USA). Variables such as SBP, the number of treatments for IDH between NV and PS/PES groups were compared using Student's $t$ test or Welch's $t$ test, if data were normally distributed. Non-normally distributed data were analyzed by Man-Whitney's $U$ test. Prevalence data were analyzed by means of chi-square or Fisher's exact probability test. The changes of serological and clinical parameters in the time course of treatment were analyzed using paired $t$ test or Wilcoxon signed-ranks test, as appropriate. Time-dependent changes of the parameters were compared using repeated-measures analysis of variance or Friedman's test, followed by a post hoc test. Significance was defined by $P$ less than 0.05 .

\section{Results}

\section{Subject characteristics}

Of the 44 enrolled patients in six dialysis centers, 40 patients ( $n=20$ each for NV and PS/PES groups) completed the entire comparative period. There were two withdrawals from each group (NV group: one moved and the other received a surgical treatment. PS/PES group: one moved and the other changed the modality from HD to hemodiafiltration.). There were no significant differences in the demographic and clinical characteristics of the patients between two groups, except the number of antihypertensive drug users and the value of ejection fraction. Patients in NV group had more difficulty to control blood pressure and better ejection fraction values than ones in PS/PES group (Table 1). There was one patient who took a vasopressor drug in NV group (data not shown).

\section{Changes in the number of treatments for IDH}

As shown in Fig. 2a, the total number of treatments was not statistically different between NV and PS/PES groups during the whole study period. However, in NV group, it decreased significantly at fifth and sixth month, compared with that in pre-observation period. In contrast, in PS/PES group, the total number of treatments did not decrease significantly.

The number of each treatment is shown in Fig. $2 b-h$. In NV group, the number of every treatment decreased at sixth month compared to that in pre-observation period. Especially, the number of dialysis discontinuation and leg elevation decreased significantly at fifth and
Table 1 Demographic and clinical characteristics of the patients enrolled

\begin{tabular}{|c|c|c|c|}
\hline & NV group & PS/PES group & $P$ \\
\hline Patients $(n)$ & 20 & 20 & \\
\hline Age (years) & $62.3 \pm 9.1$ & $61.5 \pm 10.1$ & 0.78 \\
\hline Female (\%) & $7(35 \%)$ & $6(30 \%)$ & 0.74 \\
\hline Dialysis vintage (years) & $9.2 \pm 4.8$ & $6.7 \pm 4.5$ & 0.11 \\
\hline Antihypertensive drug users (\%) & $16(80 \%)$ & $9(45 \%)$ & 0.02 \\
\hline $\begin{array}{l}\text { Antiplatelet/anticoagulant } \\
\text { users }(\%)^{\mathrm{a}}\end{array}$ & $14(82 \%)$ & $17(100 \%)$ & 0.23 \\
\hline Ejection fraction (\%) ${ }^{a}$ & $70.4 \pm 5.2$ & $60.7 \pm 8.0$ & $<0.01$ \\
\hline \multicolumn{4}{|l|}{ Comorbidities } \\
\hline Ischemic heart disease (\%) ${ }^{a}$ & $7(41 \%)$ & $12(71 \%)$ & 0.17 \\
\hline Heart failure (\%) ${ }^{a}$ & $6(35 \%)$ & $5(29 \%)$ & 1.00 \\
\hline Cerebral infarction (\%) ${ }^{\mathrm{a}}$ & $3(18 \%)$ & $2(12 \%)$ & 1.00 \\
\hline Cerebral hemorrhage $(\%)^{\mathrm{a}}$ & $0(0 \%)$ & $1(6 \%)$ & 1.00 \\
\hline BMI $\left(\mathrm{kg} / \mathrm{m}^{2}\right)$ & $24.0 \pm 5.0$ & $24.9 \pm 4.3$ & 0.57 \\
\hline White blood cell count $\left(\times 10^{3} / \mu \mathrm{L}\right)$ & $6.3 \pm 1.8$ & $6.6 \pm 2.7$ & 0.53 \\
\hline Hemoglobin (g/dL) & $11.2 \pm 0.8$ & $11.0 \pm 2.6$ & 0.66 \\
\hline Platelet $\left(\times 10^{4} / \mu \mathrm{L}\right)$ & $20.0 \pm 5.2$ & $18.5 \pm 4.9$ & 0.35 \\
\hline ESA user (\%) & $13(65 \%)$ & $10(50 \%)$ & 0.34 \\
\hline Ferritin (ng/mL) & $122.4 \pm 141.4$ & $94.2 \pm 53.8$ & 0.41 \\
\hline Phosphate (mg/dL) & $5.6 \pm 1.5$ & $5.4 \pm 1.6$ & 0.72 \\
\hline Calcium (mg/dL) & $9.1 \pm 0.7$ & $8.8 \pm 0.6$ & 0.20 \\
\hline Intact PTH (ng/mL) & $122 \pm 98$ & $162 \pm 163$ & 0.34 \\
\hline Albumin (g/dL) & $3.5 \pm 0.3$ & $3.5 \pm 0.3$ & 0.78 \\
\hline Total-cholesterol (mg/dL) & $171 \pm 36$ & $154 \pm 28$ & 0.10 \\
\hline Triglyceride (mg/dL) & $124 \pm 70$ & $142 \pm 86$ & 0.49 \\
\hline HDL-cholesterol (mg/dL) & $44 \pm 14$ & $44 \pm 15$ & 0.96 \\
\hline Ankle brachial index (right) & $1.03 \pm 0.25$ & $1.09 \pm 0.28$ & 0.51 \\
\hline Ankle brachial index (left) & $1.11 \pm 0.19$ & $1.12 \pm 0.26$ & 0.91 \\
\hline Homocysteine (nmol/mL) & $35.8 \pm 25.1$ & $34.7 \pm 18.5$ & 0.87 \\
\hline Pentosidine $(\mu \mathrm{g} / \mathrm{mL})$ & $0.415 \pm 0.218$ & $0.326 \pm 0.108$ & 0.11 \\
\hline hsCRP (mg/dL) & $0.221 \pm 0.174$ & $0.187 \pm 0.196$ & 0.57 \\
\hline Pentraxin 3 (ng/mL) & $4.04 \pm 1.68$ & $4.55 \pm 3.76$ & 0.58 \\
\hline Adrenaline (ng/mL) & $0.02 \pm 0.01$ & $0.02 \pm 0.01$ & 0.10 \\
\hline Noradrenaline(ng/mL) & $0.33 \pm 0.19$ & $0.38 \pm 0.19$ & 0.46 \\
\hline Dopamine (ng/mL) & $0.04 \pm 0.02$ & $0.05 \pm 0.02$ & 0.13 \\
\hline
\end{tabular}

$B M I$ body mass index, ESA erythropoiesis-stimulating agent, $H D L$ high-density lipoprotein, $h S C R P$ high-sensitivity C-reactive protein

$a_{n}=17$ in both $N V$ and PS/PES groups

sixth month. Conversely, in PS/PES group, the numbers of some treatments such as decrease of ultrafiltration rate and dialysis discontinuation increased and the others such as saline administration and leg elevation decreased. In addition, one patient who took a vasopressor drug in NV group could stop the medication during the study period. 

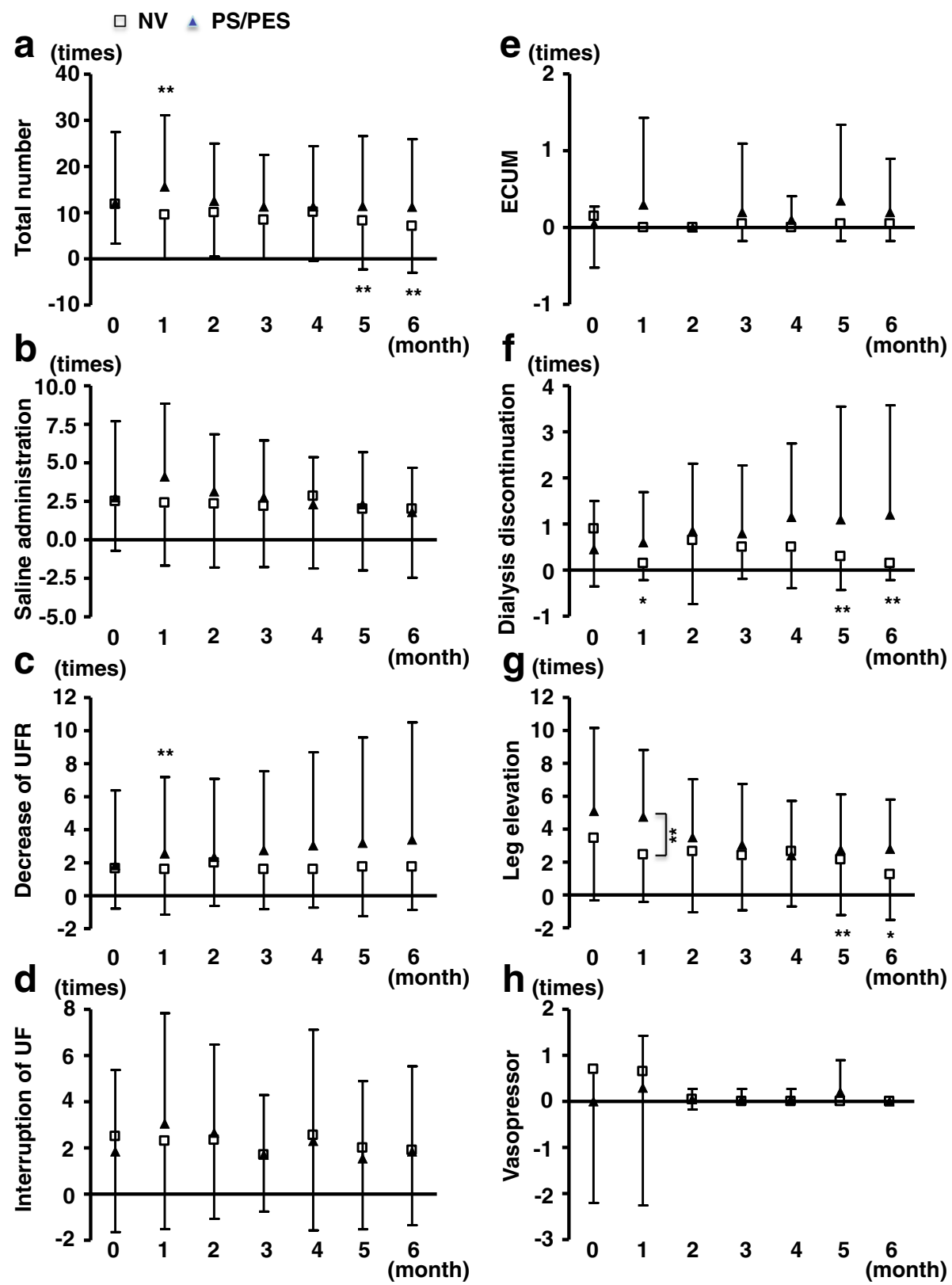

Fig. 2 The number of treatments for intradialytic hypotension in NV and PS/PES groups. a The total number of treatments was not significantly different between NV and PS/PES groups during the whole study period. However, in NV group, it decreased significantly compared with that in pre-observation period. In contrast, in PS/PES group, the total number of treatments did not decrease significantly. $\mathbf{b}-\mathbf{h}$ In NV group, the number of every treatment decreased at sixth month compared as that in pre-observation period. Especially, the number of dialysis discontinuation and leg elevation decreased significantly at fifth and sixth month. Conversely, in PS/PES group, the number of some treatments such as decrease of ultrafiltration rate and dialysis discontinuation increased and the others such as saline administration and leg elevation decreased. UFR: ultrafiltration rate. UF: ultrafiltration. ECUM: extracorporeal ultrafiltration method. All values are expressed as mean \pm SD. ${ }^{*} P<0.01 .{ }^{* *} P<0.05$

\section{Changes in SBP}

Pre-dialysis SBP, post-dialysis SBP, the lowest SBP and SBP fall were also monitored continuously (Fig. 3). In pre-observation period, there were no differences in predialysis, post-dialysis, the lowest SBP and SBP fall between NV and PS/PES groups. However, in NV group, post-dialysis and the lowest SBP were significantly higher at sixth month compared as those in PS/PES group. As for SBP fall, the average value was significantly relieved in NV group at sixth month compared as that in pre-observation period, while SBP fall was not improved in PS/PES group. Besides, the number of patients whose average SBP fall over $30 \mathrm{mmHg}$ in 1 month also decreased significantly in NV group at 


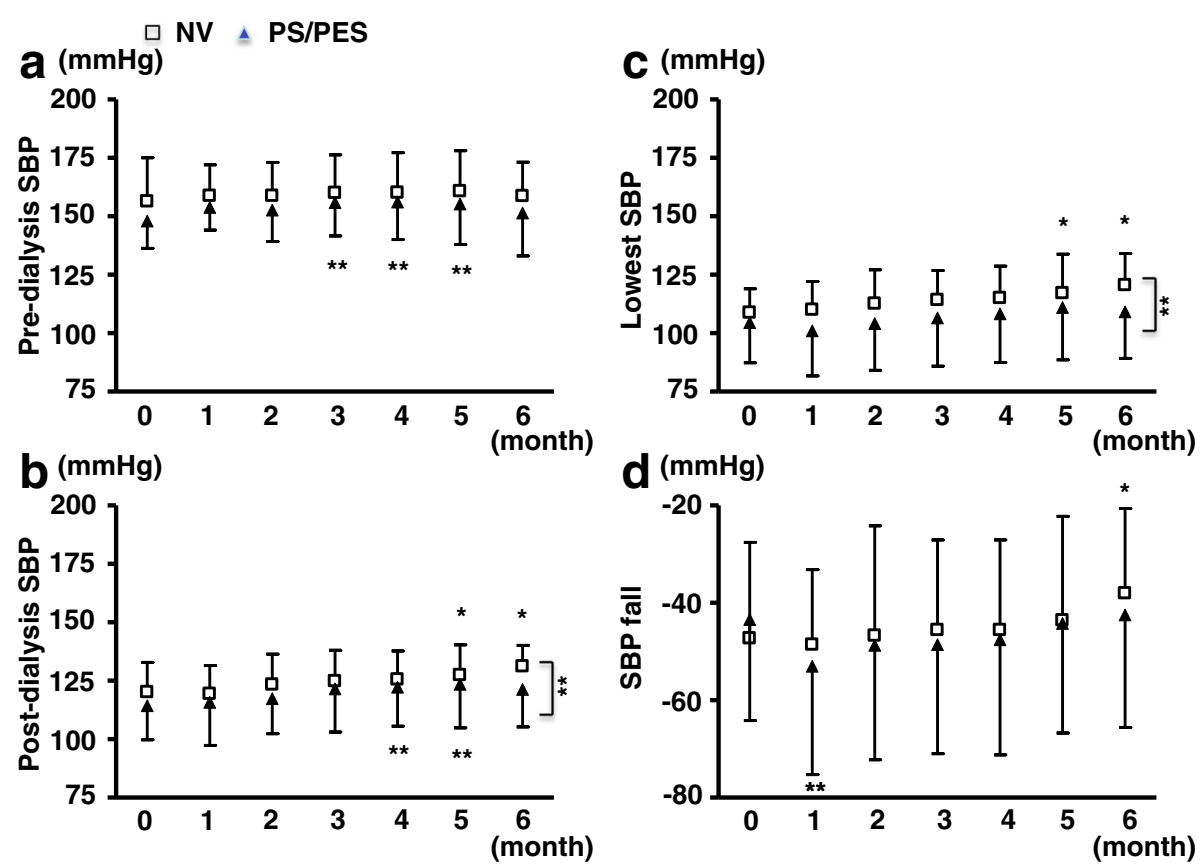

Fig. 3 Systolic blood pressure in NV and PS/PES groups. a-c In pre-observation period, there were no differences in pre-dialysis, post-dialysis, and lowest systolic blood pressure (SBP) between NV and PS/PES groups. However, in NV group, post-dialysis and the lowest SBP were significantly higher at sixth month compared to those in PS/PES group. $\mathbf{d}$ The average value of SBP fall during hemodialysis was significantly relieved in NV group at sixth month compared as that in pre-observation period, while SBP fall was not improved in PS/PES group. All values are expressed as mean \pm SD. ${ }^{*} P<0.01 .{ }^{* *} P<0.05$

sixth month (from 18 to 12 patients), but showing no statistical difference from PS/PES group (Table 2).

Of note, there were no significant differences in pre-dialysis body weight, ultrafiltration volume, CTR between both groups and no changes in the number of patients who used antihypertensive drugs or antiplatelet/ anticoagulant drugs in both groups during the whole study period (Table 3 ).

\section{Patients' clinical characteristics at sixth month}

Table 4 shows the data including the markers of nutritional states, mineral-bone disorder, anemia, lipid, arteriosclerosis, inflammation, and catecholamine at sixth month (the end of comparative period). There were no significant differences between two groups. These results indicated that nutritional status was similar between both groups and the therapy targets for anemia and mineral-bone disorder were commonly recognized in every dialysis center. NV group did not receive advantageous effects on arteriosclerosis and inflammation markers compared to PS/PES group at sixth month.

\section{Differences between NV non-responders and responders}

From the 18 patients in NV group with average SBP fall over $30 \mathrm{mmHg}$ in 1 month in pre-observation period, we divided 12 patients as NV non-responders whose SBP falls remained over $30 \mathrm{mmHg}$ at sixth month and 6 patients as NV responders whose SBP falls decreased no more than $30 \mathrm{mmHg}$ at sixth month (Table 2). Between the two groups, we examined the statistical difference of various parameters at zero month. Then, NV responders had significantly longer dialysis vintages, lower body weights, lower potassium and higher HDL cholesterol levels than NV non-responders. NV responders also had lower body mass indexes, higher ferritin and hsCRP levels, but not reaching significant difference (Table 5).

Regarding PS group, we were not able to analyze the difference between non-responders and responders statistically, because PS responders included only one case.

Table 2 The number of patients with average systolic blood pressure fall over $30 \mathrm{mmHg}$ in 1 month

\begin{tabular}{|c|c|c|c|c|}
\hline \multirow[b]{2}{*}{ NV group } & \multicolumn{2}{|c|}{ Pre-observation period (zero month) } & \multicolumn{2}{|l|}{ Sixth month } \\
\hline & $>30 \mathrm{mmHg}$ & 18 & $>30 \mathrm{mmHg}$ & $12^{\mathrm{a}}$ \\
\hline & & & $\leq 30 \mathrm{mmHg}$ & $6^{\mathrm{b}}$ \\
\hline & $\leq 30 \mathrm{mmHg}$ & 2 & $>30 \mathrm{mmHg}$ & 0 \\
\hline & & & $\leq 30 \mathrm{mmHg}$ & 2 \\
\hline \multirow[t]{4}{*}{ PS/PES group } & $>30 \mathrm{mmHg}$ & 14 & $>30 \mathrm{mmHg}$ & 13 \\
\hline & & & $\leq 30 \mathrm{mmHg}$ & 1 \\
\hline & $\leq 30 \mathrm{mmHg}$ & 6 & $>30 \mathrm{mmHg}$ & 1 \\
\hline & & & $\leq 30 \mathrm{mmHg}$ & 5 \\
\hline
\end{tabular}

${ }^{a} \mathrm{NV}$ non-responders

${ }^{\mathrm{b}} \mathrm{NV}$ responders 
Table 3 Changes in parameters related to IDH

\begin{tabular}{|c|c|c|c|}
\hline & NV group & PS/PES group & $P$ \\
\hline \multicolumn{4}{|l|}{ Pre-dialysis body weight (kg) } \\
\hline Pre-observation period (zero month) & $66.7 \pm 17.5$ & $67.7 \pm 12.4$ & 0.84 \\
\hline First month & $66.7 \pm 17.4$ & $67.9 \pm 12.4$ & 0.81 \\
\hline Second month & $66.7 \pm 17.5$ & $67.8 \pm 12.4$ & 0.83 \\
\hline Third month & $66.9 \pm 17.6$ & $68.1 \pm 12.6$ & 0.80 \\
\hline Fourth month & $66.8 \pm 17.6$ & $68.0 \pm 12.5$ & 0.81 \\
\hline Fifth month & $66.6 \pm 17.6$ & $67.8 \pm 12.7$ & 0.81 \\
\hline Sixth month & $66.6 \pm 17.5$ & $68.1 \pm 13.1$ & 0.76 \\
\hline \multicolumn{4}{|l|}{ Ultrafiltration volume (ml/session) } \\
\hline Pre-observation period (zero month) & $3071 \pm 1134$ & $3163 \pm 996$ & 0.79 \\
\hline First month & $3014 \pm 1173$ & $3066 \pm 985$ & 0.88 \\
\hline Second month & $2939 \pm 1168$ & $2988 \pm 964$ & 0.89 \\
\hline Third month & $2949 \pm 1201$ & $3129 \pm 1015$ & 0.61 \\
\hline Fourth month & $2995 \pm 1171$ & $3015 \pm 1005$ & 0.95 \\
\hline Fifth month & $3023 \pm 1305$ & $2956 \pm 1020$ & 0.86 \\
\hline Sixth month & $3028 \pm 1202$ & $3134 \pm 1018$ & 0.77 \\
\hline \multicolumn{4}{|l|}{ Cardiothoracic ratio (\%) } \\
\hline Pre-observation period (zero month) & $50.1 \pm 4.9$ & $50.7 \pm 5.3$ & 0.72 \\
\hline Sixth month & $51.4 \pm 4.5$ & $52.1 \pm 5.6$ & 0.69 \\
\hline \multicolumn{4}{|l|}{ Antihypertensive drug users (\%) } \\
\hline \multirow[t]{6}{*}{ Pre-observation period (zero month) } & $16(80 \%)$ & $9(45 \%)$ & 0.02 \\
\hline & ARB (8) & ARB (5) & \\
\hline & Ca antag. (13) & Ca antag. (4) & \\
\hline & $\beta$ blocker (3) & $\beta$ blocker (3) & \\
\hline & a blocker (1) & a blocker (1) & \\
\hline & $\alpha \beta$ blocker (1) & aß blocker (2) & \\
\hline \multirow[t]{6}{*}{ Sixth month } & $17(85 \%)$ & $10(50 \%)$ & 0.02 \\
\hline & ARB $(7)$ & ARB (6) & \\
\hline & Ca antag. (13) & Ca antag. (5) & \\
\hline & $\beta$ blocker (1) & $\beta$ blocker (4) & \\
\hline & a blocker (3) & a blocker (1) & \\
\hline & $\alpha \beta$ blocker (1) & a $\beta$ blocker (2) & \\
\hline \multicolumn{4}{|c|}{ Antiplatelet/anticoagulant users (\%) ${ }^{\mathrm{a}}$} \\
\hline \multirow[t]{8}{*}{ Pre-observation period (zero month) } & $14(82 \%)$ & $17(100 \%)$ & 0.23 \\
\hline & Aspirin (12) & Aspirin (15) & \\
\hline & Clopidogrel (1) & Clopidogrel (2) & \\
\hline & Warfarin $(0)$ & Warfarin (3) & \\
\hline & EPA (0) & $\mathrm{EPA}(0)$ & \\
\hline & O3FAE (0) & O3FAE (0) & \\
\hline & Other (3) & Other (6) & \\
\hline & Statin (1) & Statin (3) & \\
\hline \multirow[t]{8}{*}{ Sixth month } & $14(82 \%)$ & $17(100 \%)$ & 0.23 \\
\hline & Aspirin (12) & Aspirin (15) & \\
\hline & Clopidogrel (3) & Clopidogrel (3) & \\
\hline & Warfarin (1) & Warfarin (2) & \\
\hline & EPA (0) & EPA (0) & \\
\hline & O3FAE (0) & O3FAE (0) & \\
\hline & Other (3) & Other (7) & \\
\hline & Statin (1) & Statin (3) & \\
\hline
\end{tabular}

ARB angiotensin receptor blocker, $C a$ antag. calcium antagonist, EPA Epadel, O3FAE, Omega-3-fatty acid ethyl esters, Other Other antiplatelet/anticoagulant

${ }^{a} n=17$ in both NV and PS/PES groups
Table 4 Patients' clinical characteristics at sixth month

\begin{tabular}{|c|c|c|c|}
\hline & NV group & PS/PES group & $P$ \\
\hline BMI $\left(\mathrm{kg} / \mathrm{m}^{2}\right)$ & $24.0 \pm 5.0$ & $24.8 \pm 4.2$ & 0.57 \\
\hline White blood cell count $\left(\times 10^{3} / \mu \mathrm{L}\right)$ & $6.1 \pm 2.0$ & $6.7 \pm 2.3$ & 0.37 \\
\hline Hemoglobin (g/dL) & $10.6 \pm 2.5$ & $10.8 \pm 0.9$ & 0.75 \\
\hline Platelet $\left(\times 10^{4} / \mu \mathrm{L}\right)$ & $18.6 \pm 5.0$ & $18.2 \pm 4.7$ & 0.84 \\
\hline ESA user (\%) & $16(80 \%)$ & $15(75 \%)$ & 0.71 \\
\hline Ferritin $(\mathrm{ng} / \mathrm{mL})$ & $104.6 \pm 88.1$ & $88.3 \pm 55.6$ & 0.50 \\
\hline Phosphate (mg/dL) & $5.8 \pm 1.1$ & $5.2 \pm 0.9$ & 0.10 \\
\hline Calcium (mg/dL) & $8.9 \pm 0.7$ & $8.9 \pm 0.6$ & 1.00 \\
\hline Intact PTH (ng/mL) & $154 \pm 121$ & $161 \pm 152$ & 0.87 \\
\hline Albumin (g/dL) & $3.5 \pm 0.3$ & $3.5 \pm 0.2$ & 0.96 \\
\hline Total-cholesterol (mg/dL) & $169 \pm 31$ & $157 \pm 29$ & 0.20 \\
\hline Triglyceride (mg/dL) & $119 \pm 60$ & $155 \pm 115$ & 0.22 \\
\hline HDL-cholesterol (mg/dL) & $45 \pm 12$ & $45 \pm 13$ & 0.92 \\
\hline Ankle brachial index (right) & $1.00 \pm 0.28$ & $1.11 \pm 0.25$ & 0.33 \\
\hline Ankle brachial index (left) & $1.00 \pm 0.28$ & $1.08 \pm 0.23$ & 0.33 \\
\hline Homocysteine $(\mathrm{nmol} / \mathrm{mL})$ & $34.5 \pm 17.6$ & $29.6 \pm 12.0$ & 0.31 \\
\hline Pentosidine $(\mu \mathrm{g} / \mathrm{mL})$ & $0.399 \pm 0.177$ & $0.351 \pm 0.184$ & 0.40 \\
\hline $\mathrm{hsCRP}(\mathrm{mg} / \mathrm{dL})$ & $0.179 \pm 0.191$ & $0.212 \pm 0.201$ & 0.60 \\
\hline Pentraxin 3 (ng/mL) & $4.47 \pm 2.12$ & $3.71 \pm 2.51$ & 0.31 \\
\hline Adrenaline (ng/mL) & $0.02 \pm 0.01$ & $0.02 \pm 0.01$ & 0.81 \\
\hline Noradrenaline (ng/mL) & $0.44 \pm 0.24$ & $0.41 \pm 0.19$ & 0.73 \\
\hline Dopamine (ng/mL) & $0.04 \pm 0.02$ & $0.06 \pm 0.04$ & 0.15 \\
\hline
\end{tabular}

$B M I$ body mass index, ESA erythropoiesis-stimulating agent, $H D L$ high-density lipoprotein, $h s C R P$ high-sensitivity $C$-reactive protein

\section{Discussion}

In this study, we demonstrated that NV dialyzers increased post-dialysis and the lowest SBP compared as conventional PS/PES dialyzers, even though the total number of treatments for IDH decreased. The reduction of intervention for IDH correlated with the increase of SBP during HD. It gives validity to the results and supports the usefulness of $\mathrm{NV}$ as a possible method to deal with IDH.

Intradialytic blood pressure was controlled by complex mechanisms. Many factors including dry weight setting, ultrafiltration rate, nutritional status, anemia, and inflammation are involved in the maintenance of blood pressure during HD. Therefore, it is really difficult to estimate the effects of new equipment on the improvement of IDH. We intervened IDH by using hydrophilic polymer-coated PS membrane NV dialyzers. NV could reduce the number of treatments for IDH and improve intradialytic SBP (Figs. 2 and 3), even though representative influential factors on IDH such as pre-dialysis body weight, ultrafiltration rate were similar during the whole study period (Table 3). In addition, the number of patients with average SBP fall over $30 \mathrm{mmHg}$ in 1 month 
Table 5 Demographic and clinical characteristics of NV non-responders and responders

\begin{tabular}{|c|c|c|c|}
\hline & $\begin{array}{l}\text { NV } \\
\text { non-responders }\end{array}$ & $\begin{array}{l}\text { NV } \\
\text { responders }\end{array}$ & $P$ \\
\hline Patients $(n)$ & 12 & 6 & \\
\hline Age (years) & $60.8 \pm 11.6$ & $64.7 \pm 1.8$ & 0.43 \\
\hline Female (\%) & $3(25 \%)$ & $3(50 \%)$ & 0.31 \\
\hline Dialysis vintage (years) & $7.0 \pm 4.1$ & $14.0 \pm 3.5$ & $\begin{array}{l}< \\
0.01\end{array}$ \\
\hline \multirow{6}{*}{$\begin{array}{l}\text { Antihypertensive drug } \\
\text { users (\%) }\end{array}$} & $10(83 \%)$ & $5(83 \%)$ & 1 \\
\hline & ARB (3) & ARB (3) & \\
\hline & Ca antag. (8) & Ca antag. (3) & \\
\hline & $\beta$ blocker (1) & $\beta$ blocker (2) & \\
\hline & a blocker (0) & a blocker (1) & \\
\hline & aß blocker (1) & a $\beta$ blocker (0) & \\
\hline \multirow{8}{*}{$\begin{array}{l}\text { Antiplatelet/anticoagulant } \\
\text { users }(\%)^{\mathrm{a}}\end{array}$} & $7(70 \%)$ & $5(100 \%)$ & 0.49 \\
\hline & Aspirin (6) & Aspirin (4) & \\
\hline & Clopidogrel (1) & $\begin{array}{l}\text { Clopidogrel } \\
(0)\end{array}$ & \\
\hline & Warfarin (0) & Warfarin(0) & \\
\hline & EPA (0) & $\mathrm{EPA}(0)$ & \\
\hline & O3FAE (0) & O3FAE (0) & \\
\hline & Other (1) & Other (2) & \\
\hline & Statin (0) & Statin (1) & \\
\hline Ejection fraction (\%) & $70.2 \pm 5.5$ & $71.5 \pm 5.4$ & 0.69 \\
\hline \multicolumn{4}{|l|}{ Comorbidities } \\
\hline \multicolumn{4}{|c|}{ Ischemic heart disease $(\%)^{a}$} \\
\hline Heart failure (\%) ${ }^{a}$ & $3(30 \%)$ & $2(40 \%)$ & 0.85 \\
\hline Cerebral infarction (\%) ${ }^{\mathrm{a}}$ & $1(10 \%)$ & $2(40 \%)$ & 0.49 \\
\hline Cerebral hemorrhage $(\%)^{a}$ & $0(0 \%)$ & $0(0 \%)$ & 1 \\
\hline $\mathrm{BMI}\left(\mathrm{kg} / \mathrm{m}^{2}\right)$ & $25.8 \pm 5.1$ & $20.7 \pm 4.1$ & 0.05 \\
\hline $\begin{array}{l}\text { White blood cell count } \\
\left(\times 10^{3} / \mu \mathrm{L}\right)\end{array}$ & $6.43 \pm 1.73$ & $6.47 \pm 2.16$ & 0.91 \\
\hline Hemoglobin (g/dL) & $11.5 \pm 0.9$ & $11.0 \pm 0.3$ & 0.33 \\
\hline Platelet $\left(\times 10^{4} / \mu \mathrm{L}\right)$ & $20.5 \pm 5.9$ & $20.0 \pm 4.3$ & 0.93 \\
\hline ESA user (\%) & $67 \%$ & $50 \%$ & 0.86 \\
\hline Ferritin $(\mathrm{ng} / \mathrm{mL})$ & $77 \pm 68$ & $205 \pm 227$ & 0.08 \\
\hline Sodium (mEq/L) & $138 \pm 2$ & $139 \pm 2$ & 0.37 \\
\hline Potassium (mEq/L) & $5.5 \pm 0.8$ & $4.5 \pm 0.9$ & 0.02 \\
\hline Phosphate (mg/dL) & $6.1 \pm 1.6$ & $5.3 \pm 1.0$ & 0.24 \\
\hline Calcium (mg/dL) & $9.0 \pm 0.7$ & $9.4 \pm 0.8$ & 0.29 \\
\hline Intact PTH (ng/mL) & $148 \pm 105$ & $77 \pm 80$ & 0.17 \\
\hline Albumin (g/dL) & $3.6 \pm 0.3$ & $3.5 \pm 0.2$ & 0.55 \\
\hline Total-cholesterol (mg/dL) & $168 \pm 38$ & $175 \pm 39$ & 0.71 \\
\hline Triglyceride (mg/dL) & $127 \pm 73$ & $95 \pm 53$ & 0.53 \\
\hline HDL-cholesterol (mg/dL) & $38 \pm 10$ & $56 \pm 13$ & \\
\hline
\end{tabular}

Table 5 Demographic and clinical characteristics of NV non-responders and responders (Continued)

\begin{tabular}{|c|c|c|c|}
\hline & $\begin{array}{l}\text { NV } \\
\text { non-responders }\end{array}$ & $\begin{array}{l}\mathrm{NV} \\
\text { responders }\end{array}$ & $P$ \\
\hline & & & $\begin{array}{l}< \\
0.01\end{array}$ \\
\hline Ankle brachial index (right) & $1.06 \pm 0.25$ & $0.94 \pm 0.27$ & 0.40 \\
\hline Ankle brachial index (left) & $1.12 \pm 0.17$ & $1.10 \pm 0.26$ & 0.85 \\
\hline Homocysteine (nmol/mL) & $32.6 \pm 16.0$ & $46.4 \pm 39.8$ & 0.30 \\
\hline Pentosidine $(\mu \mathrm{g} / \mathrm{mL})$ & $0.46 \pm 0.23$ & $0.39 \pm 0.19$ & 0.54 \\
\hline $\mathrm{hsCRP}(\mathrm{mg} / \mathrm{dL})$ & $0.17 \pm 0.17$ & $0.34 \pm 0.17$ & 0.06 \\
\hline Pentraxin 3 (ng/mL) & $3.77 \pm 1.40$ & $5.00 \pm 2.08$ & 0.15 \\
\hline Adrenaline (ng/mL) & $0.018 \pm 0.009$ & $0.022 \pm 0.012$ & 0.40 \\
\hline Noradrenaline (ng/mL) & $0.34 \pm 0.21$ & $0.38 \pm 0.11$ & 0.69 \\
\hline Dopamine (ng/mL) & $0.033 \pm 0.018$ & $0.043 \pm 0.021$ & 0.26 \\
\hline Pre-dialysis body weight (kg) & $74.4 \pm 17.1$ & $54.0 \pm 8.6$ & 0.02 \\
\hline $\begin{array}{l}\text { Post-dialysis body weight } \\
(\mathrm{kg})\end{array}$ & $71.1 \pm 16.1$ & $51.2 \pm 8.8$ & 0.01 \\
\hline $\begin{array}{l}\text { Ultrafiltration volume } \\
\text { (ml/session) }\end{array}$ & $3604 \pm 1234$ & $2693 \pm 607$ & 0.11 \\
\hline Cardiothoracic ratio (\%) & $51.4 \pm 5.1$ & $48.3 \pm 4.7$ & 0.24 \\
\hline
\end{tabular}

$A R B$ angiotensin receptor blocker, $C a$ antag. calcium antagonist, EPA epadel, O3FAE omega-3-fatty acid ethyl esters, Other other antiplatelet/anticoagulant, $B M I$ body mass index, ESA erythropoiesis-stimulating agent, $H D L$ high-density lipoprotein, $h s C R P$ high-sensitivity C-reactive protein ${ }^{a} n=10$ in NV non-responders and $n=5$ in NV responders

decreased significantly at sixth month in NV group (Table 2). However, we could not find the significant difference of clinical characteristics that can be related to blood pressure control between NV and PS/PES groups (Table 4). Therefore, NV could show preferable effects to manage IDH compared to conventional PS/ PES dialyzers, even though the mechanism of advantageous effects on IDH by NV has not been clarified yet.

The reason why NV showed several advantages over PS/PES dialyzers is still unknown. The values of ejection fraction were significantly higher in NV group than those in PS/PES group (Table 1), though it was not sufficient to explain NV advantage in avoiding hypotension because pulse rates in NV group were not increased after HD and not different from those in PS/PES groups at sixth month (data not shown). In addition, there was no difference of ejection fraction values between NV non-responders and responders (Table 5). In our study, the improvement of IDH by NV dialyzers appeared at later time points in comparative period. In addition to pre-dialysis body weight and ultrafiltration volume, nutritional status was similar during the whole study period. Therefore, we guess that NV played some indirect roles to improve peripheral vascular response to volume depletion during HD. Hidaka et al. showed that three-month $\mathrm{HD}$ using NV increased flow-mediated dilatation of the brachial artery, which suggested the 
improvement of endothelial dysfunction [15]. The continuous use of NV could improve the dysfunction of vascular endothelial cells and reduce the number of IDH. Recently, Kakuta et al. demonstrated that NV dialyzer induces less IL-6 than the conventional dialyzers, but pre-dialysis IL-6 values did not change during 1-year observation period [23]. Plasma IL-6 levels were reported to influence the severity of arterial wall stiffness in chronic kidney disease patients [24]. Therefore, the long-term use of $\mathrm{NV}$ might suppress the progression of arteriosclerosis, resulted in decrease in the number of IDH. NV responders had significantly longer dialysis vintages, lower body weights, lower potassium, and higher HDL cholesterol levels than non-responders. NV responders also had lower body mass indexes, higher ferritin and hsCRP levels, but not reaching significant difference. Thus, NV responders possessed valuables suggesting malnutrition and microinflammation, and better lipid profiles (Table 5). NV responders had similar characteristics including low ankle brachial index as the dialysis patients with peripheral artery disease do [25, 26], which can evoke better response to NV treatment.

Consequently, our hypothesis about the role of "biocompatibility" of NV is as follows. Dialysis membrane surface is made hydrophilic. The activations of platelets and white blood cells during HD are suppressed, followed by decreased production of microparticles derived from activated platelets [15] and inflammatory cytokines [23]. Thus, microinflammation and oxidative stress production during HD are relieved. Endothelial cell function is improved and the vasoconstriction response to hypotention is recovered during HD. However, relevant factors should be investigated to clarify the mechanism of NV effects on hemodynamic status.

In our study, we failed to find significant alterations of inflammation markers such as hsCRP and PTX3 in NV group and significant differences of them compared to PS/PES group. As Kakuta et al. did, we may have to focus on the alteration of these parameters during HD. We also should have monitored the vascular response such as flow-mediated dilatation of the brachial artery, orthostatic hypotension, or skin perfusion pressure, more sensitive marker to detect peripheral artery disease than ankle brachial index, to clarify the NV effects on IDH [27].

Kakuta et al. also reported that NV dialyzer would reduce the risk of erythropoiesis-stimulating agent hyporesponsiveness by inducing less IL-6 production during HD in patients with high IL-6 concentrations than the conventional dialyzers. NV group in our study did not have an improvement of anemia management (Tables 1 and 4). Our enrolled subjects did not have high values of hsCRP and PTX3. NV effects on the improvement of anemia control would be limited to the patients with inflammation-related erythropoiesis-stimulating agent hypo-responsiveness.

A weakness of this study is its relatively small sample size that could cause unknown source of bias in the findings. The other limitation is that dialyzers for control patients were not limited to PS only, to avoid too much interference to hypotension-prone patients.

\section{Conclusions}

In summary, this prospective stratified-randomized multicenter study compared the number of treatments for IDH in DN HD patients between NV and PS/PES dialysis users. Post-dialysis SBP and the lowest SBP during HD became significantly higher in NV group than those in PS/PES group. In addition, the total number of treatments for IDH was significantly decreased in NV group. Thus, NV prevented IDH in DN patients undergoing $\mathrm{HD}$. NV responders possessed valuables suggesting malnutrition and microinflammation. Further studies are needed to clarify the NV effect on IDH.

\section{Additional file}

Additional file 1: Dialyzers of NV group. (PDF $65 \mathrm{~kb}$ )

Additional file 2: Dialyzers of PS/PES group. (PDF 57 kb)

\section{Acknowledgements}

The authors thank all the participants and our collaborators: Hiroyuki Michiwaki and Daisuke Hirose at Kawashima Dialysis Clinic and Kouji Mizuta, Hideki Hayashi, and Tadanobu Hosokawa at Yoshinogawa Medical Center. We also thank Michael Hann (Naval Medical Center San Diego) for Englishlanguage editing.

Funding

This study was funded in part by Toray Industries Inc.

Availability of data and materials

Please contact author for data requests.

Authors' contributions

$\mathrm{KT}$ designed and promoted the study. $\mathrm{HH}, \mathrm{KK}, \mathrm{HH}, \mathrm{YF}, \mathrm{MK}$, and $\mathrm{YT}$ acquired data and informed consent. MM and ACY statistically analyzed the data. TT, $\mathrm{IM}$, and HK gave critical revision of article. $\mathrm{KN}$ analyzed the results and wrote the manuscript. JM conceived and designed the study. All authors read and approved the final manuscript.

Ethics approval and consent to participate

All clinical investigations were conducted according to the principles expressed in the Declaration of Helsinki. The details of this study were explained to patients in advance, and all participants gave their written informed consent prior to their inclusion in the study. This study was reviewed and approved by the Institutional Review Board of Kawashima Hospital.

\section{Consent for publication}

We have also obtained consent to publish from the participant to report individual patient data.

\section{Competing interests}

Kenji Tsuchida, Akihiro C Yamashita, Michio Mineshima, Tadashi Tomo, Ikuto Masakane, Yoshiaki Takemoto, Hideki Kawanishi, and Jun Minakuchi have received honoraria and travel expenses for speaking at events organized by Toray Industries Inc. Kenji Tsuchida, Akihiro C Yamashita, Michio Mineshima, Tadashi Tomo, Ikuto Masakane, and Jun Minakuchi have received research 
funds from Toray Industries Inc. for other research projects. The other authors declare that they have no competing interests.

\section{Publisher's Note}

Springer Nature remains neutral with regard to jurisdictional claims in published maps and institutional affiliations.

\section{Author details}

'Tsuchida Dialysis Access Clinic, 2-10-18, Fujiidera DH building 4F, Oka, Fujiidera-shi, Osaka 583-0027, Japan. ${ }^{2}$ Yoshinogawa Medical Center, Nishichiejima 120, Kamojimachochiejima, Yoshinogawa-shi, Tokushima 776-8511, Japan. ${ }^{3}$ Kamojima Kawashima Clinic, Fukui 396-3, Kamojimacho-inoo, Yoshinogawa-shi, Tokushima 776-0033, Japan. ${ }^{4}$ Naruto Kawashima Clinic, Nishi 68-5, Otsuchodanzeki, Naruto-shi, Tokushima 772-0043, Japan. ${ }^{5}$ Wakimachi Kawashima Clinic, Tatejinja-shimominami 39-2, Ooaza-Inoshiri, Wakimachi, Mima-shi, Tokushima 779-3602, Japan. ${ }^{6}$ Seijukai Clinic, 4-5-16, Honcho, Chuo-ku, Osaka 541-0053, Japan. ${ }^{7}$ Department of Chemical Science and Technology, Faculty of Bioscience and Applied Chemistry, Hosei University, 3-7-2, Kajinocho, Koganei-shi, Tokyo 184-8584, Japan. ${ }^{8}$ Department of Clinical Engineering, Tokyo Women's Medical University, 8-1, Kawadacho, Shinjuku-ku, Tokyo 162-8666, Japan. ${ }^{9}$ Oita University Hospital Blood Purification Center, Idai-gaoka, 1-1, Hasama-machi, Yufu-shi, Oita 879-5593, Japan. ${ }^{10}$ Yabuki Hospital, 4-5-5, Shimakita, Yamagata 990-0885, Japan. ${ }^{11}$ Department of Urology, Osaka City University, 1-4-3, Asahimachi, Abeno-ku, Osaka 545-0051, Japan. ${ }^{12}$ Tsuchiya General Hospital, 3-30, Nakajimacho, Naka-ku, Hiroshima 730-8655, Japan. ${ }^{13}$ Kawashima Hospital, 1-39, Kitasakoichibancho, Tokushima-shi, Tokushima 770-0011, Japan.

Received: 16 January 2017 Accepted: 27 November 2017

Published online: 19 December 2017

\section{References}

1. Daugirdas JT. Pathophysiology of dialysis hypotension: an update. Am J Kidney Dis. 2001;38(4 Suppl 4):S11-7.

2. Shoji T, Tsubakihara Y, Fujii M, Imai E. Hemodialysis-associated hypotension as an independent risk factor for two-year mortality in hemodialysis patients. Kidney Int. 2004;66:1212-20.

3. Santoro A, Mancini E, Basile C, Amoroso L, Di Giulio S, Usberti M, et al. Blood volume controlled hemodialysis in hypotension-prone patients: a randomized, multicenter controlled trial. Kidney Int. 2002;62:1034-45.

4. Tislér A, Akócsi K, Borbás B, Fazakas L, Ferenczi S, Görögh S, et al. The effect of frequent or occasional dialysis-associated hypotension on survival of patients on maintenance haemodialysis. Nephrol Dial Transplant. 2003;18:2601-5.

5. Dasselaar JJ, Huisman RM, de Jong PE, Franssen CF. Measurement of relative blood volume changes during haemodialysis: merits and limitations. Nephrol Dial Transplant. 2005;20:2043-9.

6. Nakai S, Iseki K, Itami N, Ogata S, Kazama JJ, Kimata N, et al. An overview of regular dialysis treatment in Japan (as of 31 December 2010). Ther Apher Dial. 2012:16:483-521.

7. Zhou YL, Liu HL, Duan XF, Yao Y, Sun Y, Liu Q. Impact of sodium and ultrafiltration profiling on haemodialysis-related hypotension. Nephrol Dial Transplant. 2006;21:3231-7.

8. Spongano M, Santoro A, Ferrari G, Badiali F, Rossi M, Parrino A, et al. Continuous computerized monitoring of hemodynamic parameters during acetate dialysis, bicarbonate dialysis, and acetate-free biofiltration. Artif Organs. 1988:12:476-81.

9. Muñoz R, Gallardo I, Valladares E, Saracho R, Martínez I, Ocharan J, Montenegro J. Online hemodiafiltration: 4 years of clinical experience. Hemodial Int. 2006;10(Suppl 1):S28-32.

10. Koremoto M, Takahara N, Takahashi M, Okada Y, Satoh K, Kimura T, et al. Improvement of intradialytic hypotension in diabetic hemodialysis patients using vitamin E-bonded polysulfone membrane dialyzers. Artif Organs. 2012:36:901-10

11. Tanaka M, Hayashi T, Morita S. The roles of water molecules at the biointerface of medical polymers. Polym J. 2013:45:701-10.

12. Oshihara W, Ueno $Y$, Fujieda $H$. A new polysulfone membrane dialyzer, NV, with low-fouling and antithrombotic properties. Contrib Nephrol. 2017;189:222-9.
13. Yamaka T, Ichikawa K, Saito M, Watanabe K, Nakai A, Higuchi N, et al. Biocompatibility of the new anticoagulant dialyzer TORAYLIGHT ${ }^{\circledR}$ NV. Sci Postprint. 2014;1:e00020

14. Ronco C, Brendolan A, Nalesso F, Zanella M, De Cal M, Corradi V, et al. Prospective, randomized, multicenter, controlled trial (TRIATHRON 1) on a new antithrombogenic hydrophilic dialysis membrane. Int J Artif Organs. 2017:40:234-9.

15. Hidaka S, Kobayashi S, Maesato K, Mochida Y, Ishioka K, Oka M, et al. Hydrophilic polymer-coated polysulfone membrane improves endothelial function of hemodialysis patients: a pilot study. J Clin Nephrol Res. 2015;2:1020

16. Daniel L, Fakhouri F, Joly D, Mouthon L, Nusbaum P, Grunfeld JP, et al. Increase of circulating neutrophil and platelet microparticles during acute vasculitis and hemodialysis. Kidney Int. 2006;69:1416-23.

17. Tan KT, Tayebjee MH, Lynd C, Blann AD, Lip GY. Platelet microparticles and soluble $\mathrm{P}$ selectin in peripheral artery disease: relationship to extent of disease and platelet activation markers. Ann Med. 2005;37:61-6.

18. Namba M, Tanaka A, Shimada K, Ozeki Y, Uehata S, Sakamoto T, et al. Circulating platelet-derived microparticles are associated with atherothrombotic events: a marker for vulnerable blood. Arterioscreler Thromb Vasc Biol. 2007:27:255-6.

19. Kooman J, Basci A, Pizzarelli F, Canaud B, Haage P, Fouque D, et al. EBPG guideline on haemodynamic instability. Nephrol Dial Transplant. 2007; 22(Suppl 2):ii22-44.

20. Koda Y, Aoike I, Hasegawa S, Osawa Y, Nakagawa Y, Iwabuchi F, et al. Feasibility of intermittent back-filtrate infusion hemodiafiltration to reduce intradialytic hypotension in patients with cardiovascular instability: a pilot study. Clin Exp Nephrol. 2017;21:324-32.

21. Assimon MM, Flythe JE. Definitions of intradialytic hypotension. Semin Dial. 2017:30:464-72.

22. Chou JA, Streja E, Nguyen DV, Rhee CM, Obi Y, Inrig JK, et al. Intradialytic hypotension, blood pressure changes and mortality risk in incident hemodialysis patients. Nephrol Dial Transplant. 2017. doi:10.1093/ndt/gfx037.

23. Kakuta T, Komaba H, Takagi N, Takahashi Y, Suzuki H, Hyodo T, et al. A prospective multicenter randomized controlled study on interleukin- 6 removal and induction by a new hemodialyzer with improved biocompatibility in hemodialysis patients—a pilot study. Ther Apher Dial. 2016;20:569-78.

24. Krzanowski M, Janda K, Dumnicka P, Dubiel M, Stompór M, Kuśnierz-Cabala $B$, et al. Relationship between aortic pulse wave velocity, selected proinflammatory cytokines, and vascular calcification parameters in peritoneal dialysis patients. J Hypertens. 2014;32:142-8.

25. Takahara M, lida O, Soga Y, Kodama A, Azuma N, SPINACH study investigators. Absence of preceding intermittent claudication and its associated clinical features in patients with critical limb ischemia. J Atheroscler Thromb. 2015;22:718-25.

26. Shiraki T, lida O, Takahara M, Okamoto S, Kitano I, Tsuji Y, et al. Predictive scoring model of mortality after surgical or endovascular evascularization in patients with critical limb ischemia. J Vasc Surg. 2014;60:383-9.

27. Okamoto K, Oka M, Maesato K, Ikee R, Mano T, Moriya H, et al. Peripheral arterial occlusive disease is more prevalent in patients with hemodialysis: comparison with the findings of multidetector-row computed tomography. Am J Kidney Dis. 2006;48:269-76.

\section{Submit your next manuscript to BioMed Central and we will help you at every step:}

- We accept pre-submission inquiries

- Our selector tool helps you to find the most relevant journal

- We provide round the clock customer support

- Convenient online submission

- Thorough peer review

- Inclusion in PubMed and all major indexing services

- Maximum visibility for your research

Submit your manuscript at www.biomedcentral.com/submit
) Biomed Central 